\title{
Pyropia yezoensis peptide promotes collagen synthesis by activating the TGF- $\beta$ /Smad signaling pathway in the human dermal fibroblast cell line Hs27
}

\author{
CHO-RONG KIM ${ }^{1}$, YOUNG-MIN KIM ${ }^{2}$, MIN-KYEONG LEE ${ }^{1}$, IN-HYE KIM ${ }^{2}$, \\ YOUN-HEE $\mathrm{CHOI}^{2}$ and TAEK-JEONG NAM ${ }^{1,2}$ \\ ${ }^{1}$ Department of Food Science and Nutrition, Pukyong National University, Busan 48513; \\ ${ }^{2}$ Institute of Fisheries Sciences, Pukyong National University, Busan 46041, Republic of Korea
}

Received June 14, 2016; Accepted November 11, 2016

DOI: $10.3892 / \mathrm{ijmm} .2016 .2807$

\begin{abstract}
Pyropia yezoensis (P. yezoensis) is a marine algae that exhibits antioxidant, anti-inflammatory, antitumor and anti-aging activities. In this study, we investigated the effects of the $P$. yezoensis peptide, PYP1-5, on collagen synthesis in the human dermal fibroblast cell line Hs27. Skin aging is related to reduced collagen production and the activities of multiple enzymes, including matrix metalloproteinases (MMPs), which degrade collagen structure in the dermis, and tissue inhibitor of tissue inhibitor of metalloproteinases (TIMPs), which inhibit the action of MMPs. While collagen synthesis is associated with a number of signaling pathways, we examined the increased collagen synthesis via the upregulation of the transforming growth factor- $\beta$ (TGF- $\beta$ )/Smad signaling pathway. Using MTS assay, we found that PYP1-5 did not affect cell viability. Moreover, we confirmed that PYP1-5 increased type 1 collagen expression using enzyme-linked immunosorbent assay (ELISA), western blot analysis and quantitative PCR. In addition, we identified changes in various enzymes, as well as the mechanisms behind the PYP1-5-induced collagen synthesis. PYP1-5 decreased the MMP-1 protein and mRNA levels, and increased the TIMP-1 and TIMP-2 protein and mRNA levels. In addition, PYP1-5 activated the TGF- $\beta / \mathrm{Smad}$ signaling pathway, which increased TGF- $\beta 1, \mathrm{p}-\mathrm{Smad} 2$ and p-Smad3 expression, while inhibiting Smad7, an inhibitor of the TGF- $\beta /$ Smad pathway. Furthermore, PYP1-5 upregulated transcription factor specificity protein 1 (Spl) expression, which is reportedly involved in type 1 collagen expression. These findings indicate that PYP1-5 activates the TGF- $\beta / \mathrm{Smad}$ signaling pathway, which subsequently induces collagen synthesis in Hs27 cells.
\end{abstract}

Correspondence to: Professor Taek-Jeong Nam, Department of Food Science and Nutrition, Pukyong National University, 45 Yongso-Ro, Nam-gu, Busan 48513, Republic of Korea

E-mail: namtj@pknu.ac.kr

Key words: Pyropia yezoensis, Hs27 cells, collagen synthesis, transforming growth factor- $\beta / \mathrm{Smad}$

\section{Introduction}

In recent years, the average human lifespan has increased due to economic growth and advancements in modern medicine. As a result, people have begun to pay more attention to skin health and beauty (1). Many research efforts have focused on the identification of strategies with which to inhibit and delay skin aging, and many cosmetic and food products related to skin anti-aging have been developed (2).

Skin aging is driven by intrinsic and extrinsic factors that cause structural degradation and alterations. Intrinsic aging occurs naturally with aging, while extrinsic aging is caused by external factors, such as ultraviolet (UV) radiation, gravity and air pollution (3). The characteristics of intrinsic aging include reduced levels of extracellular matrix components, such as collagen and elastin, which decrease skin elasticity and tension (4). Therefore, maintaining collagen levels in the dermis is important for maintaining healthy skin. Skin is composed of various layers, including the epidermis composed of epithelial tissue and the dermis composed of connective tissue and subcutaneous layer. The epidermis protects the skin from microbial pathogens, UV light and chemical compounds. The dermis is composed of fibrous proteins, including ground substance, collagen and elastin. It is an important layer that constitutes $>90 \%$ of the skin (5). A variety of substrates, including collagen and elastin in the extracellular matrix (ECM), are made by dermal fibroblasts. There are several types of collagen, which accounts for $80-90 \%$ of the dermis. Type 1 collagen constitutes approximately $85 \%$ of total collagen and provides tension, elasticity and flexibility to the skin as it is entangled in elastic fibers (6). Its structure is maintained by several enzymes; matrix metalloproteinases (MMPs) secreted by fibroblasts degrade collagen, while MMP activity is inhibited by tissue inhibitor of tissue inhibitor of metalloproteinases (TIMPs). During the aging process, MMP expression gradually increases and TIMP expression decreases, promoting collagen degradation and reducing skin elasticity $(7,8)$.

Transforming growth factor- $\beta$ (TGF- $\beta$ ) is a multifunctional cytokine with three isoforms, TGF- $\beta 1$, TGF- $\beta 2$ and TGF- $\beta 3$. TGF- $\beta$ helps regulate cellular processes, such as cell growth, differentiation, migration, apoptosis and the production of 
various ECM components, including collagen, elastin and fibronectin $(9,10)$. TGF- $\beta$ interacts with two types of receptors containing type 1 and 2 receptors (serine/threonine kinase receptors). To activate the TGF- $\beta /$ Smad signaling pathway, the TGF- $\beta 1$ ligand first binds to type 2 receptors (TGF- $\beta$ RII) at the cell surface, which allows for the phosphorylation of the GS domain of TGF- $\beta$ RI, activating downstream signaling. The complex then enters the nucleus from the cytoplasm, where it can regulate the expression of target genes by binding to promoters and co-factors to activate transcription $(11,12)$.

Recent studies have found that marine algae, including red, brown and green algae, are rich in nutrients with a variety of bioactive functions. For example, Pyropia yezoensis (P. yezoensis), a red alga, is cultivated abundantly in East Asian countries, including China, Japan and Korea (13). $P$. yezoensis is composed of $25-40 \%$ carbohydrates and $25-50 \%$ proteins based on its dry weight, and is a good source of physiologically active substances (14).P. yezoensis has numerous biological functions, including antioxidant, antitumor, antifatigue and anti-inflammatory activities, and has been shown to reduce blood pressure and protect against UVA-induced photoaging (15-18). Although a number of studies are in progress to examine the biological effects of $P$. yezoensis, no studies have yet examined its effects against skin aging using human dermal fibroblasts, at least to the best of our knowledge. In this study, we found that the $P$. yezoensis peptide, PYP1-5, affected collagen synthesis in Hs27 cells. Furthermore, we determined the intracellular mechanisms responsible for PYP1-5 induced-collagen synthesis, focusing on the TGF- $\beta /$ Smad signaling pathway and enzymes related to collagen expression.

\section{Materials and methods}

Preparation of P. yezoensis peptide PYP1-5. PYP1-5 (D-P-KG-K-Q-Q-A-I-H-V-A-P-S-F) was prepared as described previously (19). The $15 \mathrm{~N}$-terminal residues of PYP1-5 were synthesized by Peptron (Daejeon, Korea). PYP1-5 was purified using a Shimadzu Prominence high-performance liquid chromatography (HPLC) apparatus and the software package Class-VP version 6.14 (Shimadzu, Kyoto, Japan), with a C18 column (Capcell Pak; Shiseido, Tokyo, Japan) in 0.1\% trifluoroacetic acid (TFA)/water, a gradient of $10-70 \%$ acetonitrile (0-20\% acetonitrile for $2 \mathrm{~min}, 20-50 \%$ acetonitrile for $10 \mathrm{~min}$, and $50-80 \%$ acetonitrile for $2 \mathrm{~min}$ ) in $0.1 \%$ TFA, a flow rate of $1.0 \mathrm{ml} / \mathrm{min}$, and UV detection at $220 \mathrm{~nm}$. The molecular mass of PYP1-5 was confirmed to be 1,622 kDa based on mass spectrometry (HP 110 Series LC/MSD).

Cell culture. The human skin fibroblast cell line Hs27, was purchased from the American Type Culture Collection (ATCC, Manassas, VA, USA). The cells were maintained in complete Dulbecco's modified Eagle's medium (DMEM) with $10 \%$ fetal bovine serum (FBS; HyClone, Logan, UT, USA), $100 \mathrm{U} / \mathrm{ml}$ penicillin, and $100 \mathrm{mg} / \mathrm{ml}$ streptomycin in a humidified $5 \% \mathrm{CO}_{2}$ incubator at $37^{\circ} \mathrm{C}$. The $\mathrm{Hs} 27$ cells were cultured to $70-80 \%$ confluence in a $100-\mathrm{mm}$ diameter plate and were used between passage numbers 5 and 15 .

MTS assay. Hs27 cell viability was estimated using a CellTiter 96 AQueous Nonradioactive Cell Proliferation assay (Promega, Madison, WI, USA). The cells were plated in 48-well plates at a density of $2 \times 10^{4}$ cells/well, and subsequently treated with PYP1-5 (250, 500 and 1,000 ng/ml) in serum-free medium (SFM) for $24 \mathrm{~h}$. The cells were then incubated with $10 \mu \mathrm{l}$ of MTS solution for $30 \mathrm{~min}$ at $37^{\circ} \mathrm{C}$, and the absorbance was quantified spectroscopically at $490 \mathrm{~nm}$ using a microplate reader (Benchmark microplate reader; Bio-Rad Laboratories, Hercules, CA, USA). Cell viability was calculated as the ratio of absorbance of treated cells to that of untreated cells.

Procollagen type I C-peptide (PIP) EIA assay. Procollagen was measured with a PIP EIA assay kit (Takara Bio Inc., Tokyo, Japan). The cells were inoculated in 6-well plates at a density of $1 \times 10^{5}$ cells/well and incubated for $24 \mathrm{~h}$ in SFM containing PYP1-5 (250, 500 and $1,000 \mathrm{ng} / \mathrm{ml})$. After $24 \mathrm{~h}$, the supernatant was collected from each well and tested with the PIP EIA kit following the manufacturer's instructions.

Treatment with TGF- $\beta$ RI inhibitor (SB431542). The cells were incubated for $2 \mathrm{~h}$ with $10 \mu \mathrm{M} \mathrm{SB} 431542$ (Tocris, Bristol, UK) prior to treatment with PYP1-5.

Whole-cell protein lysate extraction. The $\mathrm{Hs} 27$ cells were seeded in $100-\mathrm{mm}$ dishes and cultured to $80 \%$ confluence. The cells were treated for $24 \mathrm{~h}$ with PYP1-5 $(250,500$ and $1,000 \mathrm{ng} / \mathrm{ml}$ ), washed 2 times in phosphate-buffered saline, and scraped on ice in lysis buffer $(50 \mathrm{mM}$ Tris- $\mathrm{HCl}, \mathrm{pH} 7.4$, $150 \mathrm{mM} \mathrm{NaCl}, 0.5 \%$ sodium deoxycholate, $1 \%$ Triton X-100, $0.1 \%$ SDS, 2 mM EDTA) containing protease inhibitor $(1 \mathrm{mg} / \mathrm{ml}$ aprotinin, $1 \mathrm{mg} / \mathrm{ml}$ leupeptin, $1 \mathrm{mg} / \mathrm{ml}$ pepstatin A, $200 \mathrm{mM} \mathrm{Na}_{3} \mathrm{VO}_{4}, 500 \mathrm{mM} \mathrm{NaF}$ and $100 \mathrm{mM}$ phenylmethylsulfonyl fluoride). The cell extracts were centrifuged at $14,000 \mathrm{rpm}$ for $10 \mathrm{~min}$, and the supernatant was collected for use in western blot analysis.

Western blot analysis. Sample proteins $(30 \mu \mathrm{g})$ were separated with $5-15 \%$ sodium dodecyl sulfate-polyacrylamide gel electrophoresis (SDS-PAGE), and then transferred onto polyvinylidene fluoride (PVDF) membranes (Millipore, Billerica, MA, USA). The membranes were blocked with $1 \%$ bovine serum albumin in TBS-T $(10 \mathrm{mM}$ Tris- $\mathrm{HCl}$, $\mathrm{pH} 7.5,150 \mathrm{mM} \mathrm{NaCl}, 0.1 \%$ Tween-20), probed with specific primary antibodies, and then probed with the secondary antibodies. Signals were detected using SuperSignal West Pico Chemiluminescent Substrate (Thermo Fisher Scientific, Inc., Rockford, IL, USA). The following primary and secondary antibodies were used: anti-collagen I (COL-1; sc-59772, anti-mouse, 1:1,000), anti-elastin (sc-166543, anti-mouse, 1:1,000), anti-MMP-1 (sc-21731, anti-mouse, 1:1,000), antiTIMP-1 (sc-5538, anti-rabbit, 1:2,000), anti-TIMP-2 (sc-5539, anti-rabbit, 1:2,000), anti-TGF- $\beta 1$ (sc-146, anti-rabbit, 1:1,000), anti-p-Smad2 (sc-135644, anti-rabbit, 1:500), anti-Smad2 (sc-6200, anti-goat, 1:1,000), anti-p-Smad3 (sc-130218, anti-rabbit, 1:500), anti-Smad7 (sc-11392, anti-rabbit, 1:2,000) and anti-glyceraldehyde 3-phosphate dehydrogenase (GAPDH) (sc-25778, anti-rabbit, 1:2,000) (all from Santa Cruz Biotechnology, Inc, Santa Cruz, CA, USA), anti-Smad3 (\#9513, anti-rabbit, 1:1,000; Cell Signaling Technology, Danvers, MA, USA), donkey anti-goat IgG (A50-101P, 1:10,000; Bethyl Laboratories, Inc., Montgomery, TX, USA), 
Table I. The oligonucleotide primer sequences used in the real-time PCR.

\begin{tabular}{|c|c|c|c|}
\hline Gene & Accession no. & Sequence $\left(5^{\prime}-3^{\prime}\right)$ & Amplicon (bp) \\
\hline COL1A1 & NM_000088.3 & $\begin{array}{l}\text { F: AGGGCCAAGACGAAGACATC } \\
\text { R: AGATCACGTCATCGCACAACA }\end{array}$ & 138 \\
\hline COL1A2 & NM_000089.3 & $\begin{array}{l}\text { F: TCTGGATGGATTGAAGGGACA } \\
\text { R: CCAACACGTCCTCTCTCACC }\end{array}$ & 126 \\
\hline Elastin & XM_011515875.1 & $\begin{array}{l}\text { F: ATGCACACTGGTGCAGAGAG } \\
\text { R: TGTAAGCACACAGGCAGGTC }\end{array}$ & 98 \\
\hline$T G F-\beta 1$ & NM_000660.5 & $\begin{array}{l}\text { F: AGCGACTCGCCAGAGTGGTTA } \\
\text { R: GCAGTGTGTTATCCCTGCTGTCA }\end{array}$ & 130 \\
\hline$M M P-1$ & NM_002421.3 & $\begin{array}{l}\text { F: CCCAAAAGCGTGTGACAGTAAG } \\
\text { R: CTTCCGGGTAGAAGGGATTTG }\end{array}$ & 113 \\
\hline TIMP-1 & NM_003254.2 & $\begin{array}{l}\text { F: TGACATCCGGTTCGTCTACA } \\
\text { R: TGCAGTTTTCCAGCAATGAG }\end{array}$ & 102 \\
\hline TIMP-2 & NM_003255.4 & $\begin{array}{l}\text { F: GCGGTCAGTGAGAAGGAAGTGGA } \\
\text { R: GAGGAGGGGGCCGTGTAGATAAAC }\end{array}$ & 140 \\
\hline GAPDH & NM_001256799.2 & $\begin{array}{l}\text { F: ACCCACTCCTCCACCTTTGA } \\
\text { R: TGGTGGTCCAGGGGTCTTAC }\end{array}$ & 157 \\
\hline
\end{tabular}

COL1A1, collagen type I $\alpha$; TGF- $\beta 1$, transforming growth factor- $\beta 1$; MMP- 1 , matrix metalloproteinase- 1 ; TIMP- 1 , tissue inhibitor of metalloproteinase-1; GAPDH, glyceraldehyde 3-phosphate dehydrogenase.

goat anti-mouse IgG-HRP (sc-2031, 1:10,000; Santa Cruz Biotechnology, Inc) and goat anti-rabbit IgG (\#7074, 1:10,000; Cell Signaling Technology).

Quantitative PCR ( $q P C R)$. The Hs27 cells seeded in 6-well plates were cultured to $80 \%$ confluence and incubated in SFM containing PYP1-5 $(250,500$ and $1,000 \mathrm{ng} / \mathrm{ml})$ for $24 \mathrm{~h}$. Total RNA was isolated from the cells using TRIzol reagent (Invitrogen, Carlsbad, CA, USA), and the extracted RNA was used as a template for cDNA synthesis using oligo(dT) (Intron Biotechnology Inc., Seongnam, Korea). The PCR amplification mixtures (total volume, $20 \mu \mathrm{l}$ ) contained $10 \mu \mathrm{l}$ of TOPreal qPCR 2X PreMIX SYBR-Green (Enzynomics Inc., Daejeon, Korea), $1 \mu 1$ of sense primer, $1 \mu \mathrm{l}$ of anti-sense primer, $2 \mu \mathrm{l}$ of cDNA template, and $6 \mu 1$ of RNase-free water. qPCR was performed using the Eco Real-Time PCR system (Illumina Inc., San Diego, CA, USA) using the following amplification conditions: pre-incubation at $95^{\circ} \mathrm{C}$ for $10 \mathrm{~min}, 40$ cycles of $95^{\circ} \mathrm{C}$ for $10 \mathrm{sec}$, annealing at $60^{\circ} \mathrm{C}$ for $15 \mathrm{sec}$, and elongation at $72^{\circ} \mathrm{C}$ for $15 \mathrm{sec}$. Gene expression levels were normalized to those of GAPDH and calculated using the comparative $\Delta \Delta \mathrm{C}_{\mathrm{T}}$ method, as previously described (20). The oligonucleotide primers used for PCR are listed in Table I.

Statistical analysis. All samples were analyzed in triplicate. The results are expressed as the means \pm standard deviation (SD). To determine statistical significance, analysis of variance (ANOVA) was conducted using SPSS software (SPSS, Inc., Chicago, IL, USA). A value of $\mathrm{p}<0.05$ was considered to indicate a statistically significant difference.

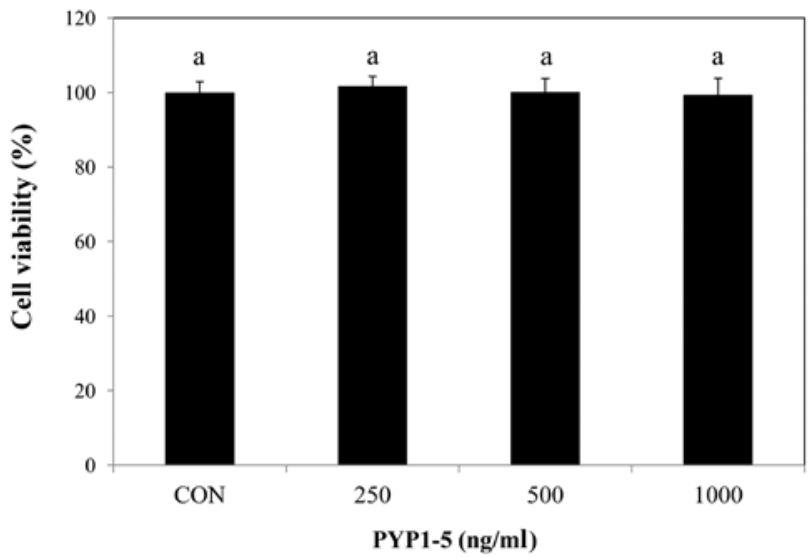

Figure 1. Cytotoxicity of PYP1-5 to Hs27 cells. The cells were seeded in 48 -well plates at a density of $2 \times 10^{4}$ cells/well with medium supplemented with $10 \%$ FBS. Following incubation, the cells were treated with PYP1-5 (250, 500 and $1,000 \mathrm{ng} / \mathrm{ml}$ ) for $24 \mathrm{~h}$. Cell viability was determined by MTS assay. The results are presented as the means \pm SD of 3 independent experiments. Bars labeled with the same letters indicate no statistical significance.

\section{Results}

Effects of PYP1-5 on Hs27 cell viability. We used MTS assay to determine PYP1-5 cytotoxicity to Hs27 cells. Fig. 1 shows the effects of various concentrations $(250,500$ and $1,000 \mathrm{ng} / \mathrm{ml})$ of PYP1-5 on Hs27 cell viability. The PYP1-5-treated cells exhibited similar effects on viability at concentrations of 250,500 and $1,000 \mathrm{ng} / \mathrm{ml}$ as the untreated cells and had no significant cytotoxicity. 
A

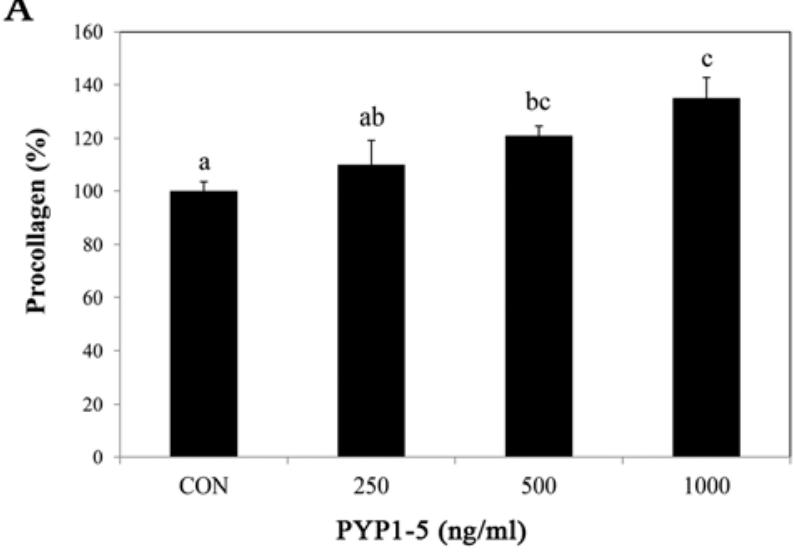

$\mathrm{C}$

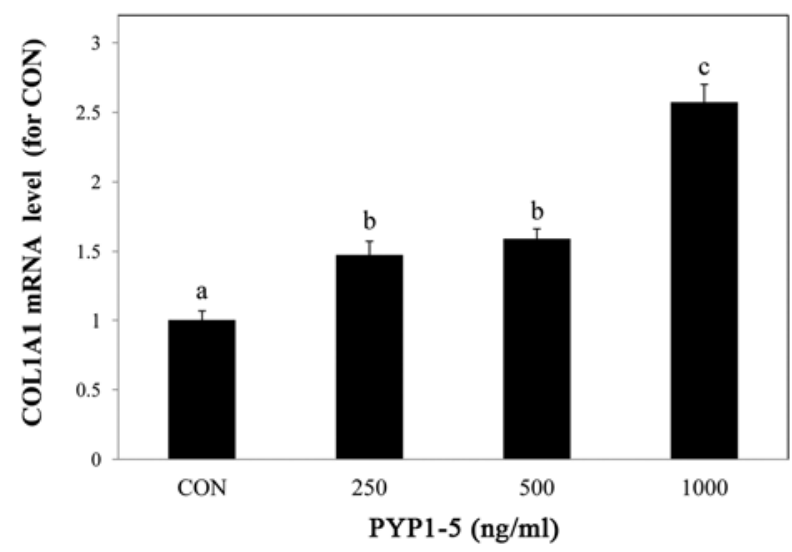

B
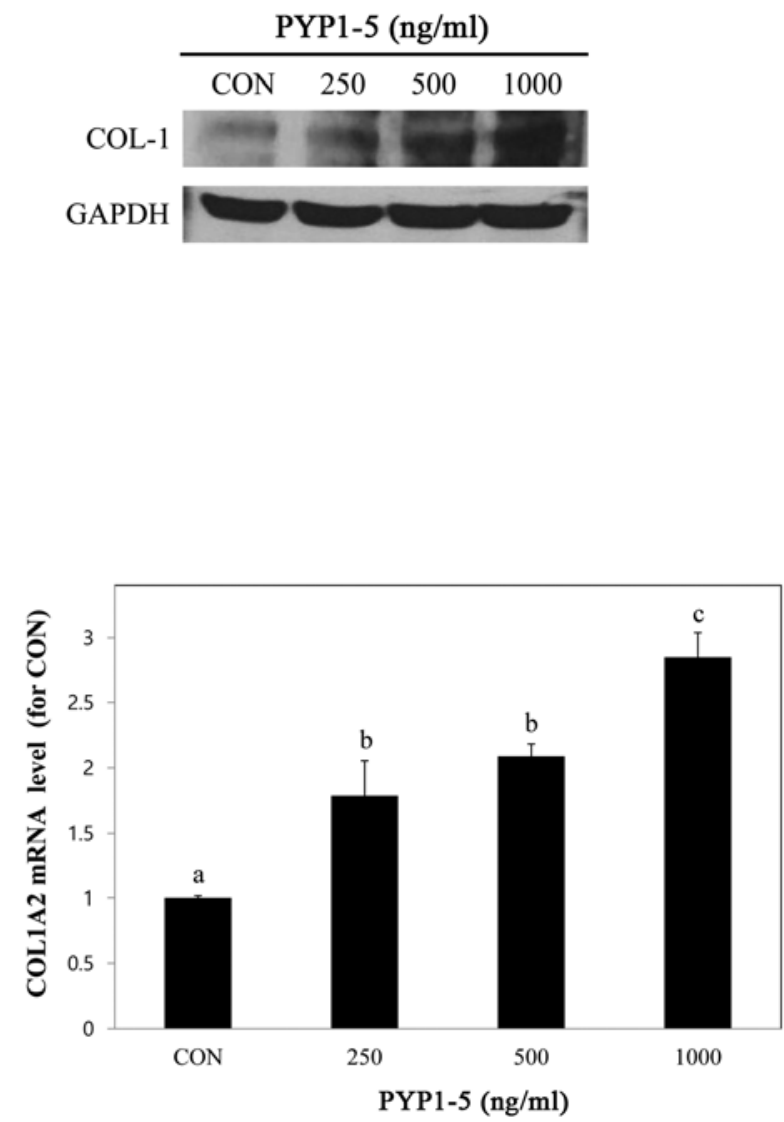

Figure 2. Effect of PYP1-5 on the expression of type I collagen in Hs27 cells. (A) Procollagen expression was investigated using the PIP EIA kit assay. (B) Type I collagen protein expression was examined with a western blot analysis. (C) Collagen type I $\alpha 1$ (COL1A1)and COL1A2 mRNA levels were examined by qPCR The results are presented as the means \pm SD of 3 independent experiments. Bars labeled with different letters indicate statistically significant differences $(\mathrm{p}<0.05)$.

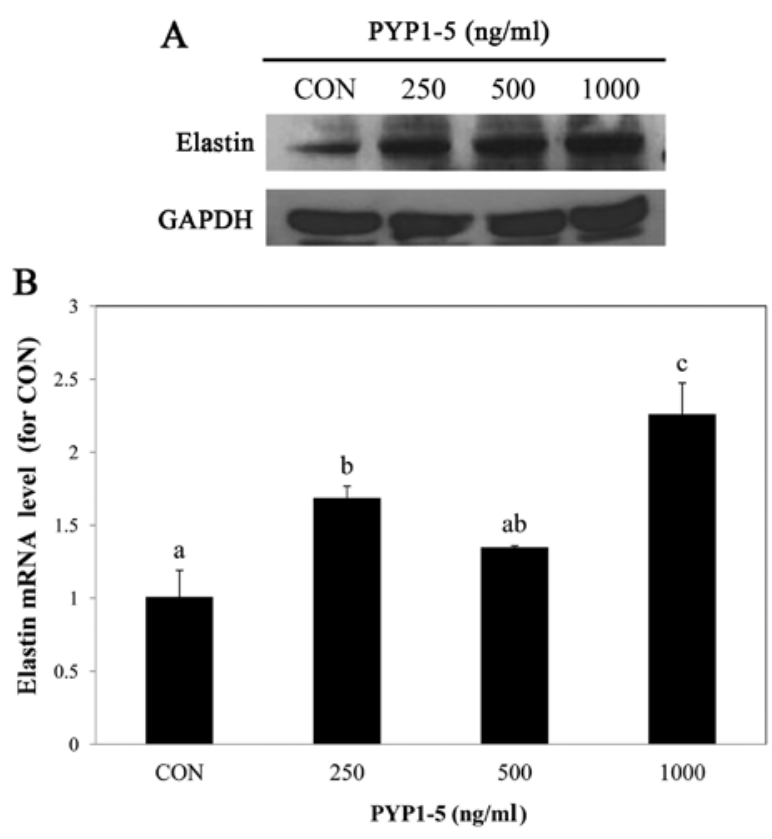

Figure 3. Effect of PYP1-5 on elastin expression in Hs27 cells. The cells were cultured in 100-mm dishes with PYP1-5 (250, 500 and 1,000 $\mathrm{ng} / \mathrm{ml})$ for $24 \mathrm{~h}$, after which cellular protein and total RNA were isolated. (A) Protein expression levels were assessed by western blot analysis. (B) mRNA expression levels were quantified by qPCR. The results are presented as the means \pm SD of 3 independent experiments. Bars labeled with different letters indicate statistically significant differences $(\mathrm{p}<0.05)$.
PYP1-5 promotes type I collagen synthesis. To determine whether PYP1-5 affects collagen synthesis, we performed a PIP EIA assay. After treating the Hs27 cells with various concentrations of PYP1-5, we measured procollagen products in the cells and found that procollagen product levels increased in a dose-dependent manner (Fig. 2A). Using western blot analysis, we confirmed that the type 1 collagen protein expression levels were increased (Fig. 2B). Type 1 collagen is composed of two $\alpha 1$ (I) chains and one $\alpha 2$ (I) chain, which are encoded by two genes, COL1A1 and COL1A2, respectively (21). We further investigated the above-mentioned by qPCR and found that both the COLIA1 and COLIA2 mRNA expression levels increased in a dose-dependent manner (Fig. 2C).

PYP1-5 increases elastin expression. Elastin is an important component of connective tissue, such as collagen and is located between collagen in the dermis, providing elasticity and flexibility to the skin. With age, elastin decomposes, resulting in reduced skin elasticity and increased skin aging $(22,23)$. In this study, to examine the effect of PYP1-5 on elastin in Hs27 cells, we performed western blot analysis and qPCR and found that the elastin protein and mRNA expression levels increased following treatment with PYP1-5 (Fig. 3).

PYP1-5 decreases MMP-1 expression and increases TIMP-1 and -2 expression. To confirm the regulatory effects of PYP1-5 
A
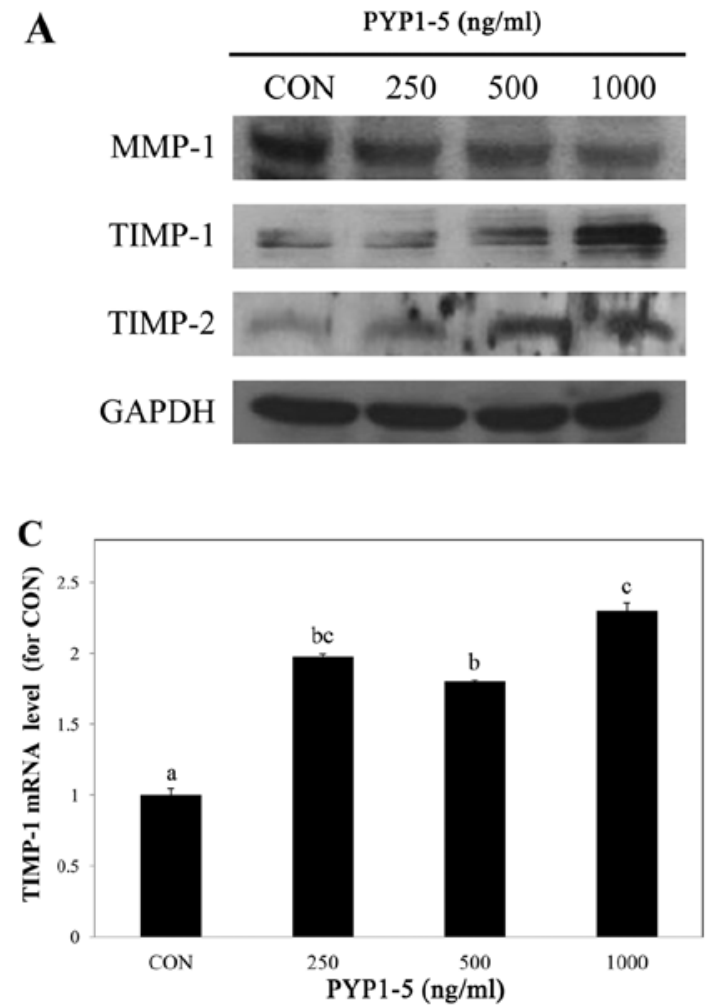

B
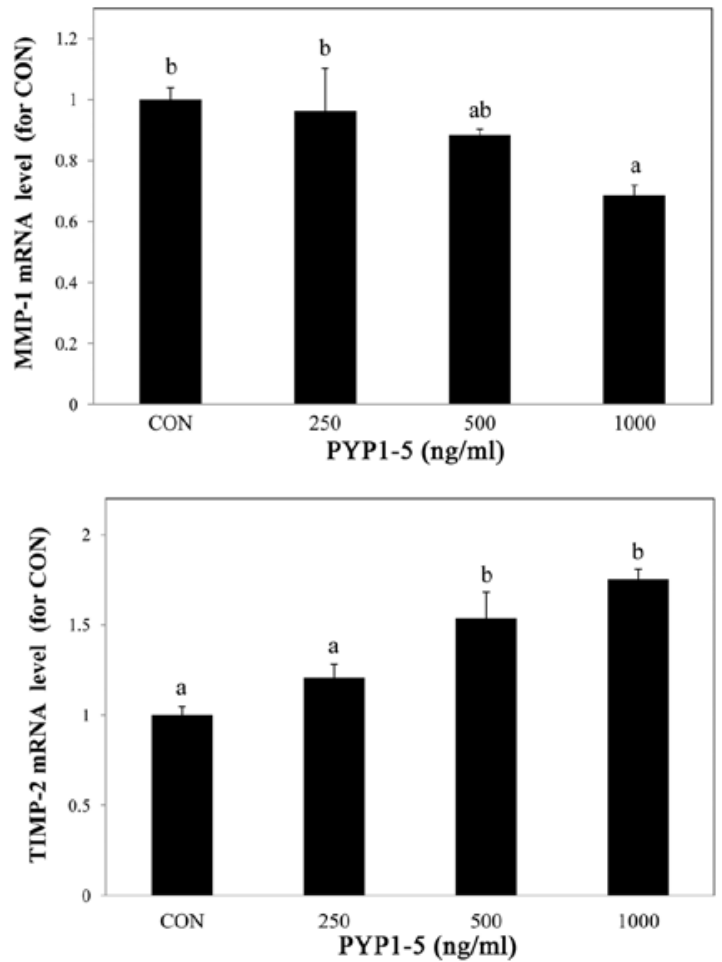

Figure 4. Effect of PYP1-5 on matrix metalloproteinase-1 (MMP-1), tissue inhibitor of metalloproteinase-1 (TIMP-1) and TIMP-2 protein and mRNA expression levels in Hs27 cells. (A) Protein expression levels were assessed by western blot analysis. (B and C) mRNA expression levels were quantified by qPCR. The results are presented as the means \pm SD of 3 independent experiments. Bars labeled with different letters indicate statistically significant differences ( $\mathrm{p}<0.05)$.

on ECM synthesis enzymes, we examined MMP-1 and TIMP-1 and -2 protein and mRNA expression by western blot analysis and qPCR, respectively. Following treatment of the cells with PYP1-5 for $24 \mathrm{~h}$, the MMP-1 protein and mRNA expression levels decreased in a dose-dependent manner (Fig. 4A and B), while the TIMP-1 and -2 protein and mRNA expression levels increased (Fig. 4A and C). These results indicate that PYP1-5 regulates collagen synthesis by reducing MMP-1 expression and inducing TIMP-1 and -2 expression.

PYP1-5 activates the TGF- $\beta /$ Smad signaling pathway. We then investigated the mechanisms through which PYP1-5 promotes type 1 collagen expression in Hs27 cells. Since the TGF- $\beta$ /Smad pathway is the major signaling pathway of collagen synthesis in the dermis (24), we assessed whether it is involved in PYP1-5-induced type 1 collagen expression.

To investigate the regulatory effects of PYP1-5 on the TGF- $\beta /$ Smad signaling pathway, we measured downstream protein and mRNA expression levels in Hs27 cells using by western blot analysis and qPCR, respectively. We confirmed that PYP1-5 increased TGF- $\beta 1$ ligand protein and mRNA expression levels in a dose-dependent manner (Fig. 5A and B). In addition, treatment with PYP1-5 increased the TGF- $\beta$ RII and $\mathrm{p}-\mathrm{Smad} 2 / 3$ protein levels. Treatment of the Hs27 cells with PYP1-5 also decreased the Smad7 protein levels, an inhibitor of the TGF- $\beta /$ Smad signaling pathway (Fig. 5C). These results indicate that treatment of the Hs 27 cells with PYP1-5 activates the TGF- $\beta /$ Smad signaling pathway. To further investigate the involvement of the TGF- $\beta /$ Smad pathway in PYP1-5-induced collagen synthesis, we used a specific inhibitor of TGF- $\beta$ RI,
SB431542 $(10 \mu \mathrm{M})$. Treatment with SB431542 downregulated the PYP1-5-induced upregulation of $\mathrm{p}-\mathrm{Smad} 2 / 3$, a downstream target of TGF- $\beta /$ Smad signaling (Fig. 6A) and attenuated the effects of PYP1-5 on the MMP-1 protein, and TIMP-1 and TIMP-2 mRNA levels (Fig. 6A and B). In addition, treatment with SB431542 reduced the PYP1-5-induced COL1A1 and COL1A2 mRNA levels (Fig. 6C). These data suggest that PYP1-5 regulates collagen synthesis via the TGF- $\beta /$ Smad signaling pathway.

PYP1-5 increases the expression of specificity protein 1 (Spl) transcription factor via the TGF- $\beta /$ Smad signaling pathway. $\mathrm{Spl}$ is an essential zinc finger transcription factor of Smaddependent positive regulation of collagen synthesis that is induced by TGF- $\beta$. The Sp1 transcription factor regulates multiple biological processes, such as tumorigenesis, apoptosis, cell cycle and angiogenesis, and induces type I procollagen synthesis in fibroblasts (25). The Smad3/4 complex induces the trans-activation of the human COL1A1 and COL1A2 promoter in normal skin fibroblasts $(26,27)$. In this study, we confirmed the effect of PYP1-5 on Sp1 protein levels induced by the the TGF- $\beta /$ Smad signaling pathway and found that treatment with PYP1-5 increased Sp1 protein expression (Fig. 7).

\section{Discussion}

Interest in anti-aging has grown with the increase in life expectancy. In particular, many efforts have been made to prevent skin aging (28) and much research has been dedicated to skin health and beauty. Skin aging is classified as either intrinsic or extrinsic. Intrinsic aging occurs due to a reduction in the 
A

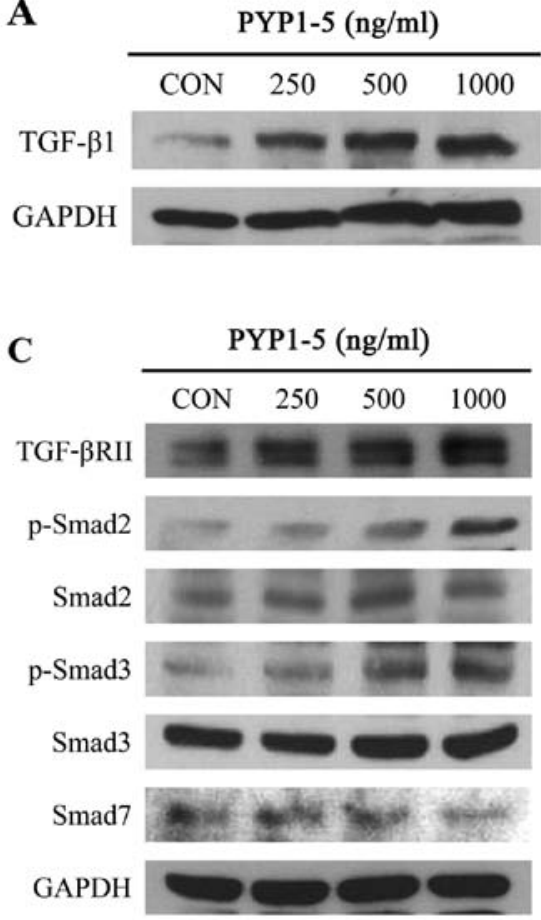

B

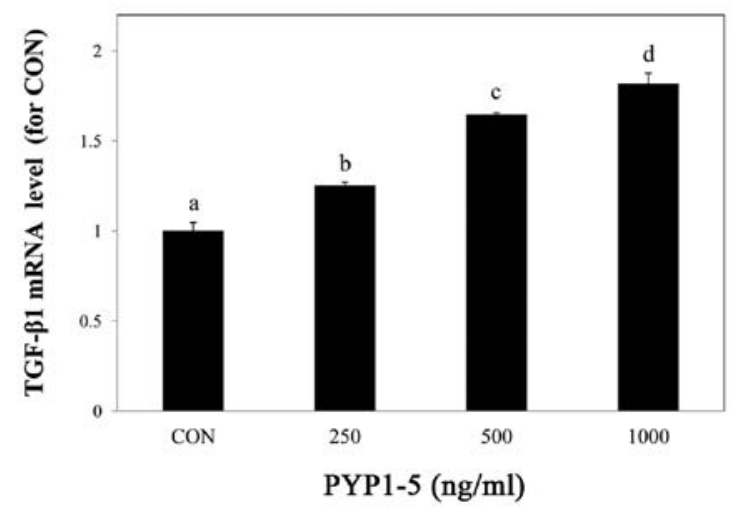

Figure 5. PYP1-5 activation of the transforming growth factor- $\beta$ (TGF- $\beta$ )/Smad signaling pathway in Hs27 cells. (A-C) Protein expression levels were assessed by western blot analysis and the mRNA expression levels were quantified by qPCR. The results are presented as the means \pm SD of 3 independent experiments. Bars labeled with different letters indicate statistically significant differences $(\mathrm{p}<0.05)$.

levels of ECM components, such as collagen and elastin, with age (29). Since collagen, the predominant component of the dermis, must be maintained to prevent the skin aging process, it is important to prevent its decomposition.

Various bioactive ingredients have been identified in many marine algae species, several of which have been studied for their anti-aging effects on skin, including anti-photoaging, anti-free radical activity, moisturization, and collagen biosynthesis (30). It has been demonstrated that $P$. yezoensis extract exerts a protective effect against UVA radiation on skin fibroblasts (18). However, the effects of $P$. yezoensis on collagen synthesis in human dermal fibroblasts remain unclear. In this study, we examined the $P$. yezoensis peptide, PYP1-5, for its anti-aging function by promoting collagen synthesis in human dermal fibroblasts. First, we investigated whether PYP1-5 induced cytotoxicity in Hs27 cells. We found that the PYP1-5-treated cells had a similar viability as the untreated cells (Fig. 1), suggesting that PYP1-5 was non-toxic to Hs27 cells. In the dermis, collagen gradually decomposes due to extrinsic and intrinsic factors, which promotes wrinkle formation and skin aging (31). PYP1-5 increased procollagen synthesis in a dosedependent manner, with a maximum increase of $35 \%$ more than the untreated cells (Fig. 2A). In addition, PYP1-5 upregulated type 1 collagen protein levels and COL1A1 and COL1A2 mRNA expression (Fig. 2B and C). These results indicate that PYP1-5 promotes collagen synthesis.

Elastin is another vital component of the skin, as it is a protein that is located between collagen in the dermis that provides elasticity and flexibility to the skin (23). Following the treatment of the Hs27 cells with PYP1-5, the elastin protein and mRNA expression levels increased (Fig. 3), suggesting that PYP1-5 promotes the synthesis of other ECM products.
Further research is required to elucidate its effects on other ECM components, such as hyaluronan and fibronectin. In the dermis, various MMP enzymes degrade collagen, while TIMP enzymes inhibit MMP activity (8). We confirmed that PYP1-5 suppressed the MMP-1 protein and mRNA expression levels (Fig. 4A and B), and enhanced the TIMP-1 and -2 protein and mRNA expression levels (Fig. 4A and C).

TGF- $\beta$ is the major activator of the collagen synthesis process in skin fibroblasts. The process is also related to the TGF- $\beta /$ Smad signaling pathway (32). PYP1-5 upregulated the TGF- $\beta 1$ protein and mRNA levels in a dose-dependent manner (Fig. 5A and B). Moreover, we confirmed that PYP1-5 increased TGF- $\beta$ RII, which resulted in Smad2 and Smad3 phosphorylation (Fig. 5C). This forms a complex with Smad4, which can translocate to the nucleus. To confirm that PYP1-5-induced collagen synthesis was caused by TGF- $\beta / \mathrm{Smad}$ signaling pathway activation, we treated the Hs27 cells with SB431542, a specific inhibitor of TGF- $\beta$ RI. Treatment with SB431542 decreased TGF- $\beta /$ Smad signaling pathway activation by PYP1-5 (Fig. 6A). In addition, PYP1-5-induced Smad2/3 activation was inhibited by SB431542, suggesting that the phosphorylation of Smad2/3 is mediated by PYP1-5 treatment. The effects of PYP1-5 on MMP-1 and TIMP-1 and -2 regulation were attenuated by treatment with SB431542 (Fig. 6A and B). Moreover, the PYP1-5-induced increase in COL1A1 and COL1A2 mRNA expression was decreased by treatment with SB431542 (Fig. 6C), indicating that PYP1-5-induced collagen synthesis is regulated by TGF- $\beta / \mathrm{Smad}$ signaling pathway activation. The Sp1 transcription factor, which is induced by TGF- $\beta$ /Smad signaling pathway activation, regulates type I procollagen expression (26). In this study, following treatment with PYP1-5, Sp1 protein expression increased (Fig. 7). This 
A
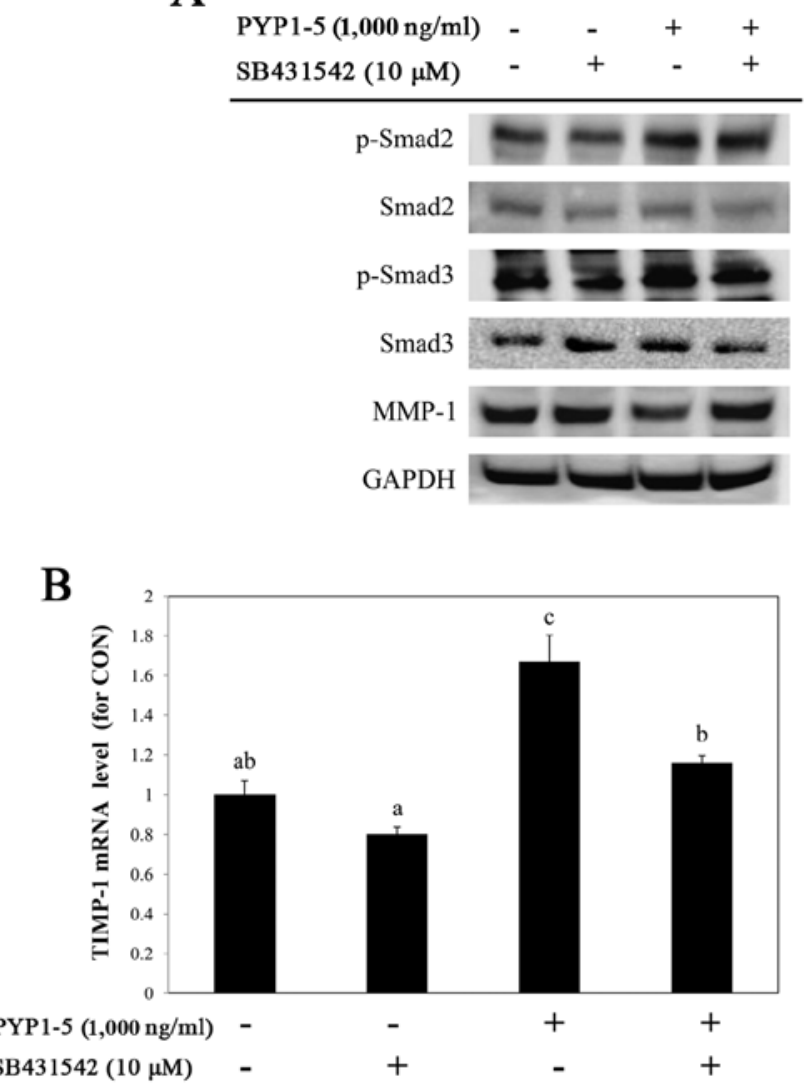

C

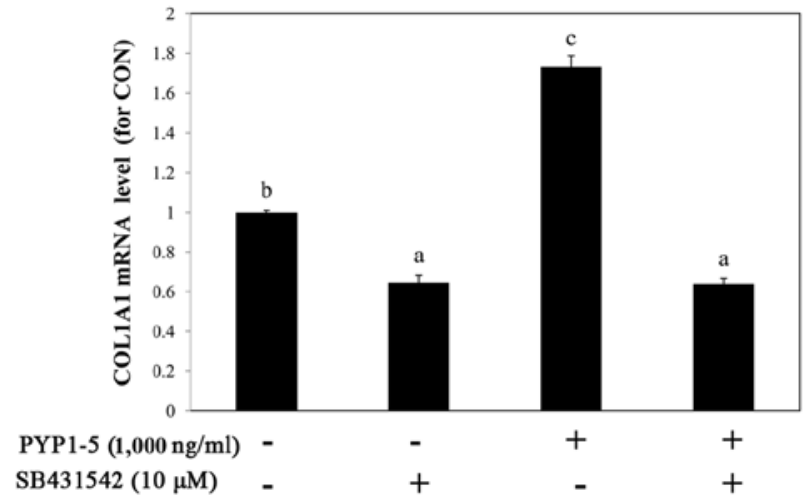

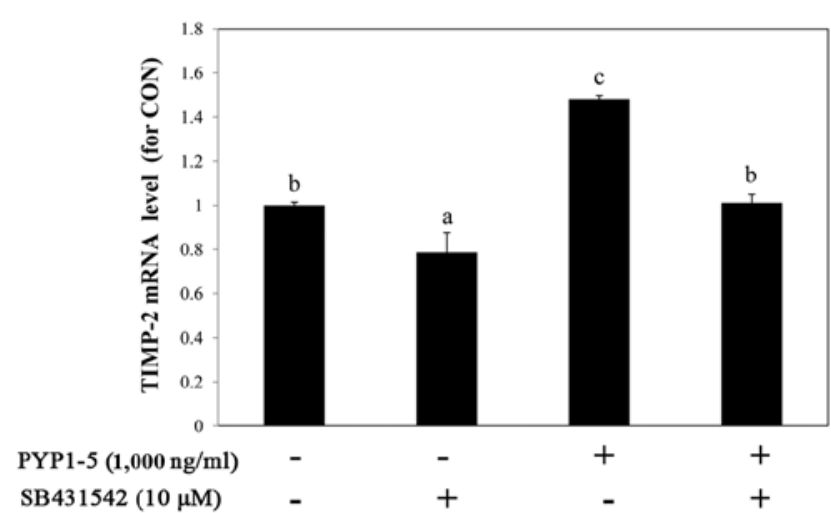

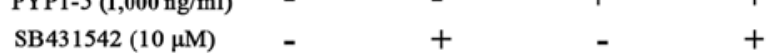

Figure 6. Effect of $10 \mu \mathrm{M} \mathrm{SB} 431542$ on PYP1-5-induced collagen synthesis in Hs27 cells. (A) Protein expression was assessed by western blot analysis. (B and C) mRNA expression levels were quantified by qPCR. The results are presented as the means \pm SD of 3 independent experiments. Bars labeled with different letters indicate statistically significant differences $(\mathrm{p}<0.05)$.

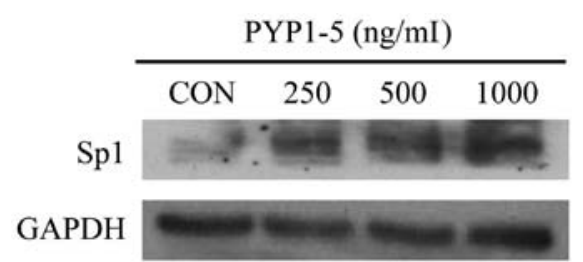

Figure 7. Effect of PYP1-5 on specificity protein 1 (Sp1) protein expression in Hs27 cells. Cells were treated with PYP1-5 for $24 \mathrm{~h}$. Protein extracts were prepared and examined by western blot analysis.

demonstrates that the treatment of Hs27 cells with PYP1-5 affects transcription.
In conclusion, the findings of this study demonstrate that PYP1-5 promotes type 1 collagen synthesis in Hs27 cells. Moreover, the TGF- $\beta /$ Smad signaling pathway may be important in mediating the effects of PYP1-5 on collagen synthesis. Our results suggest that PYP1-5 may have beneficial effects on intrinsic skin aging.

\section{Acknowledgements}

This study was supported by the Basic Science Research Program through the National Research Foundation of Korea (NRF) funded by the Ministry of Education (grant no. 2012R1A6A1028677). 


\section{References}

1. Kim SH, Yong HJ, Shin C and Ko SG: Research of traditional herbal medicines for anti-aging, inhibition effect of wrinkle and whitening effect in the skin. Kor J Ori Physiol Pathol 22: 691-698, 2008

2. Mukherjee PK, Maity N, Nema NK and Sarkar BK: Bioactive compounds from natural resources against skin aging. Phytomedicine 19: 64-73, 2011.

3. Farage MA, Miller KW, Elsner P and Maibach HI: Intrinsic and extrinsic factors in skin ageing: A review. Int J Cosmet Sci 30 : 87-95, 2008

4. Naylor EC, Watson RE and Sherratt MJ: Molecular aspects of skin ageing. Maturitas 69: 249-256, 2011.

5. Costin GE and Hearing VJ:Human skin pigmentation: Melanocytes modulate skin color in response to stress. FASEB J 21: 976-994, 2007.

6. Yoon JH, Kim J, Lee H, Kim SY, Jang HH, Ryu SH, Kim BJ and Lee TG: Laminin peptide YIGSR induces collagen synthesis in Hs27 human dermal fibroblasts. Biochem Biophys Res Commun 428: 416-421, 2012.

7. Kim EJ, Kim MK, Jin XJ, Oh JH, Kim JE and Chung JH: Skin aging and photoaging alter fatty acids composition, including $11,14,17$-eicosatrienoic acid, in the epidermis of human skin. J Korean Med Sci 25: 980-983, 2010.

8. Kähäri VM and Saarialho-Kere U: Matrix metalloproteinases in skin. Exp Dermatol 6: 199-213, 1997.

9. Dennler S, Goumans MJ and ten Dijke P: Transforming growth factor $\beta$ signal transduction. J Leukoc Biol 71: 731-740, 2002.

10. Amento EP and Beck LS: TGF- $\beta$ and wound healing. In Ciba Foundation Symposium 157 - Clinical Applications of TGF- $\beta$. John Wiley \& Sons Ltd., Chichester, pp115-136, 1991.

11. Czuwara-Ladykowska J, Sementchenko VI, Watson DK and Trojanowska M: Ets1 is an effector of the transforming growth factor- $\beta$ (TGF- $\beta$ ) signaling pathway and an antagonist of the profibrotic effects of TGF- $\beta$. J Biol Chem 277: 20399-20408, 2002

12. Verrecchia $F$ and Mauviel A: Transforming growth factor- $\beta$ signaling through the Smad pathway: Role in extracellular matrix gene expression and regulation. J Invest Dermatol 118: 211-215, 2002.

13. Kitano Y, Murazumi K, Duan J, Kurose K, Kobayashi S, Sugawara T and Hirata T: Effect of dietary porphyran from the red alga, Porphyra yezoensis, on glucose metabolism in diabetic KK-Ay mice. J Nutr Sci Vitaminol (Tokyo) 58: 14-19, 2012.

14. Jiang LF: The polysaccharides from porphyra yezoensis suppress the denaturation of bighead carp myofibrillar protein. Int J Biol Macromol 68: 18-20, 2014.

15. Kwon MJ and Nam TJ: Porphyran induces apoptosis related signal pathway in AGS gastric cancer cell lines. Life Sci 79: 1956-1962, 2006.

16. Shin ES, Hwang HJ, Kim IH and Nam TJ: A glycoprotein from Porphyra yezoensis produces anti-inflammatory effects in liposaccharide-stimulated macrophages via the TLR4 signaling pathway. Int J Mol Med 28: 809-815, 2011.
17. Qian L, Zhou Y and Ma JX: Hypolipidemic effect of the polysaccharides from Porphyra yezoensis. Int J Biol Macromol 68: 48-49, 2014.

18. Ryu J, Park SJ, Kim IH, Choi YH and Nam TJ: Protective effect of porphyra-334 on UVA-induced photoaging in human skin fibroblasts. Int J Mol Med 34: 796-803, 2014.

19. Lee MK, Kim YM, Kim IH, Choi YH and Nam TJ: Pyropia yezoensis peptide protects against dexamethasone-induced muscle atrophy through the down-regulation Atrogin1/MAFbx and MuRF1 in mouse C2C12 myotubes. Mol Med Rep (In press).

20. Livak KJ and Schmittgen TD: Analysis of relative gene expression data using real-time quantitative PCR and the 2(- $\Delta \Delta \mathrm{C}(\mathrm{T}))$ method. Methods 25: 402-408, 2001.

21. Shoulders MD and Raines RT: Collagen structure and stability. Annu Rev Biochem 78: 929-958, 2009.

22. Ryhanen L and Uitto J: Elastic fibers of the connective tissue. Biochem Physiol Skin 1: 433-447, 1983.

23. Sephel GC and Davidson JM: Elastin production in human skin fibroblast cultures and its decline with age. J Invest Dermatol 86: 279-285, 1986.

24. Choi MS, Yoo MS, Son DJ, Jung HY, Lee SH, Jung JK, Lee BC, Yun YP, Pyo HB and Hong JT: Increase of collagen synthesis by obovatol through stimulation of the TGF-beta signaling and inhibition of matrix metalloproteinase in UVB-irradiated human fibroblast. J Dermatol Sci 46: 127-137, 2007.

25. Wierstra I: Sp1: emerging roles - beyond constitutive activation of TATA-less housekeeping genes. Biochem Biophys Res Commun 372: 1-13, 2008.

26. Park JH, Kim SR, An HJ, Kim WJ, Choe M and Han JA: Esculetin promotes type I procollagen expression in human dermal fibroblasts through MAPK and PI3K/Akt pathways. Mol Cell Biochem 368: 61-67, 2012.

27. Zhang W, Ou J, Inagaki Y, Greenwel P and Ramirez F: Synergistic cooperation between $\mathrm{Sp} 1$ and Smad3/Smad4 mediates transforming growth factor $\beta 1$ stimulation of $\alpha 2(\mathrm{I})$-collagen (COL1A2) transcription. J Biol Chem 275: 39237-39245, 2000.

28. Kim YM, Jung HJ, Choi JS and Nam TJ: Anti-wrinkle effects of a tuna heart $\mathrm{H}_{2} \mathrm{O}$ fraction on $\mathrm{Hs} 27$ human fibroblasts. Int $\mathrm{J}$ Mol Med 37: 92-98, 2016.

29. El-Domyati M, Attia S, Saleh F, Brown D, Birk DE, Gasparro F, Ahmad $\mathrm{H}$ and Uitto J: Intrinsic aging vs. photoaging: A comparative histopathological, immunohistochemical, and ultrastructural study of skin. Exp Dermatol 11: 398-405, 2002.

30. Samarakoon K and Jeon YJ: Bio-functionalities of proteins derived from marine algae - A review. Food Res Int 48: 948-960, 2012.

31. Varani J, Warner RL, Gharaee-Kermani M, Phan SH, Kang S, Chung JH, Wang ZQ, Datta SC, Fisher GJ and Voorhees JJ: Vitamin A antagonizes decreased cell growth and elevated collagen-degrading matrix metalloproteinases and stimulates collagen accumulation in naturally aged human skin. J Invest Dermatol 114: 480-486, 2000.

32. Leask A and Abraham DJ: TGF- $\beta$ signaling and the fibrotic response. FASEB J 18: 816-827, 2004 